\title{
9. Who can you trust? Medical news, the public and what reporters think about public relations sources
}

\section{ABSTRACT}

Research on the effects of medical news stories on the public has demonstrated that consumers make decisions about personal health care options and choices sometimes exclusively based on stories published by the media. Given the news media's ability to set the agenda for what the lay public, government policymakers and even health professionals consider topical and important, medical news reporting has an added sense of responsibility to be timely, reliable and accurate. Public relations practitioners involved in medical promotion can be the behind-the-scenes providers of information and access to important sources in medical news production. This relationship has been an emerging area of research focus in the US but has received scant attention in Australia. Just as in other areas of reporting, the relational dynamics between reporter and PR source are often conflicting and contradictory. This article will explore the views of 25 Australian medical reporters in a mixed method study on their relationship with public relations practitioners through the construct of trust. The findings indicate that most medical reporters, although acknowledging the increasing influence of public relations on medical news production, generally do not trust public relations sources, especially those in the corporate sector. However, if ongoing PR sources are considered reliable and trustworthy, then the relationship can become one of trust and interdependence.

Keywords: health journalism, medical news, public relations, trust, sources

\author{
PATRIZIA FURLAN \\ University of South Australia, Adelaide.
}


I N 1998 a respected medical journal, The Lancet, published a peer-reviewed paper which observed a causal link between the Measles Mumps Rubella vaccine and autism in children. The 13 authors of this controversial paper (Wakefield et. al, 1998) had reportedly specified that 'we did not prove an association between measles, mumps and rubella vaccine and the syndrome described' (Bedford \& Elliman, 2010, 340: c655). However, according to Bedford \& Elliman (2010), during the press conference one of the researchers recommended a single dose vaccine for each disease rather than a combined dose of all three, a comment which generated sustained media interest. Although the research claims from the small sample of children studied $(n=12)$ were immediately condemned by the scientific community (see for example, Lee et al, 1998) the damage had been done. Despite little evidence to the contrary, public trust in the MMR vaccine had been severely compromised with an increasing number of parents refusing to immunise their children fearing they would become autistic. Cases of the potentially deadly measles began to spike creating further alarm while immunisations dropped dramatically. Twelve years after the article's publication, the editors of The Lancet retracted the article on 6 February 2010 (Editors, The Lancet, 2010). It can be argued that the media did its job in picking up apparent inconsistencies during the press conference. However, the relentless negative publicity about the vaccine despite protestations from the wider scientific community about its safety, significantly altered public perceptions about an important health topic. This case illustrates the inherent complexities in reporting medical news to the public who can be swayed to change health behaviours as a result of media attention. It also demonstrates that trust is a construct which takes years to nurture yet can immediately fracture.

Public trust in institutions of authority such as in government or finance has taken a battering in a post 9/11 world. Recent and varied global events from the Eurozone crisis to the 2010 devastating oil spill in the Gulf of Mexico, described as the United States' worst environmental disaster (Uhlmann, 2011), have further eroded public trust in the decision making and public accountability of those in power. Given the media's place in democratic societies as a press ideal 'to afflict the comfortable and comfort the afflicted' (Schultz, 1998, p. 3), public trust in the Fourth Estate confers the profession legitimacy as well as privileged access to information. However, public trust in the news media has also been tenuous at best. Examples of journalists' unethical behaviour, 
poor reporting standards and intrusions in peoples' privacy have challenged the public's faith in the media both in Europe (Brants \& de Haan, 2010) and in the United States (Vanacker \& Belmas, 2009). Recently, an Australian opinion poll conferred journalism as one of the least trusted out of 30 professions surveyed on ethics and honesty (Morgan, 2012). Given this negative impression of the news media overall, it is noteworthy that medical news can still set the agenda for what the lay public, government policy-makers and even health professionals consider topical and important (Wang \& Gantz, 2007; Schwitzer et al., 2005; Levi, 2001). Medical news reporting therefore appears to have an added sense of responsibility to be timely, accurate and reliable in order to retain public trust. According to Arroyave (2012), analysing media content is not enough to understand how health issues are portrayed in the news media; it is journalism's normative practices which are pivotal: 'the dynamics of news production shape the content of health news, which, in turn, limits the quality of health information'(p. 195). This paper will discuss the behind-thescenes process of medical news gathering within the construct of trust in the relationship between reporters and public relations sources which has received scant academic attention in this country. Whether trust is a collective concept between entities, such as media organisations and their stakeholder publics, or whether it is trust on an individual, relational level between the professions, the concept is often difficult to define, as well as fragile and elusive (Kramer \& Cook, 2004, p. 1).

\section{Defining trust}

In the extensive literature on its conceptualisations, trust has been viewed not only as a social resource but also as an economic benefit (Vanacker \& Belmas, 2009). Trust has been considered a crucial ingredient for social cohesion: 'The greater the level of trust within a community, the greater the likelihood of cooperation. And cooperation itself breeds trust' (Putnam, 1993, p. 171). The notion of trust is also a critical ingredient in interpersonal relationships (Ledingham \& Bruning, 1998; Hon \& Grunig, 1999). In journalism, the broad concept of trust refers to its public obligations to deliver accurate and timely news on which informed decisions are made about current debates or controversies. One of the core professional values which distinguishes trained journalists from other mass communicators, is the public expectation that reporters' stories are truthful and can be trusted. Varying professional Codes of Ethics in journalism practised in Western countries attest to the importance 
of 'public trust' in the media's watchdog role of scrutinising those in power on behalf of the powerless. In Australia, the Code, as outlined by unionised members, states that journalists 'inform citizens and animate democracy':

They give a practical form to freedom of expression. Many journalists work in private enterprise, but all have these public responsibilities. They scrutinise power, but also exercise it, and should be accountable. Accountability engenders trust. Without trust, journalists do not fulfil their public responsibilities. (MEAA Code of Ethics, 2012)

Trust espoused by collectives such as the general public, organisations and professions, includes the generalised view of the entire 'membership'. According to Kramer (2010), in collective trust, 'it is not the person in the role that is trusted so much as the system of expertise that produces and maintains the role-appropriate behaviour of role occupants' (p. 89).

Another interpretation of trust relevant to journalism, is that on a relational, interpersonal level between reporters and their sources (Richards, 2010). As Leon Sigal (1973) noted decades ago, sources 'make' the news and news is 'what sources say' and cultivating them is a fundamental tool of newsgathering. According to Yoon (2005), journalists determine informants' credibility based on a number of factors including perceptions of their information as fair, accurate and trustworthy. These are similar constructs used to determine journalists' own professionally credible reporting routines. On an individual level, trust has been broadly defined as a predictive, confident or optimistic evaluation about others' behaviours, intentions and motives (Lewicki, McAllister \& Bies, 1998). According to Mayer, Davis and Schoorman (1995) trust is 'the willingness of a party to be vulnerable to the actions of another party based on the expectation that the other will perform a particular action important to the trustor, irrespective of the ability to monitor or control that other party' (p. 712). There is therefore a benevolent willingness by the trustor to be exposed to possible risk and uncertainty. Hon and Grunig (1999) postulated that trust contains the three dimensions of integrity, dependability and competence. The former is defined as 'the belief that an organisation is fair and just... dependability: the belief that an organisation will do what it says it will do... and competence: the belief that an organisation has the ability to do what it says it will do' (p.3). Although this research was on an organisational level, it can be extrapolated to detect trust in interpersonal relationships. 


\section{Public relations and the news}

Public relations practitioners 'have played the role of source, providing information subsidies to journalists to influence the media agenda, or at least to get favourable publicity' (Shin \& Cameron, 2004, p. 401-402). Promotional material (including press kits and multimedia releases) sent to newsrooms, is a cost-effective news-gathering technique as well as cheap publicity for a client or organisation (Marconi, 2004; Guth \& Marsh, 2003). Public relations practitioners have long been used as intermediary sources, providing general or specialist reporters with relevant information, story ideas and hard-to-access interviewees for news stories. However, the relationship has been historically fraught, with 'love-hate' tensions between the professions well documented in the scholarly literature (for example, Shin \& Cameron, 2005; White \& Hobsbawm, 2007; Sterne, 2010; Tilley \& Hollings, 2008). DeLorme \& Fedler (2003) found a deep-rooted paradox evident in the relationship as journalists have routinely sought easily-available information from public relations sources in order to write their stories, yet consider them contemptible. In recent times, the fragmentation of the news industry, onerous deadline pressures in a relentless 24 hour news cycle, and staffing attrition have contributed to an increased reliance on free, pre-packaged material supplied by the public relations industry which, in contrast, has become well-resourced and a primary sourcing conduit even in 'quality' media organisations (Lewis et al, 2008; Macnamara, 2012).

\section{Relational parameters}

There has been much scholarly attention on the perceptions and attitudes of journalists towards public relations practitioners over the past 40 years to determine how the relationship affects the reporters' news gathering decision making. The public relations literature has also explored how the relationship can be improved as interlinked issues of trust, respect and credibility predominate (Jahansoozi, 2006; Sallot \& Johnson, 2006; Hung, 2005). Critical scholarship has focused on the increasing influence of public relations on news production, blurring the boundary between the professions (for example, Davis, 2003; Davies, 2008; Burton, 2007; Lewis et al, 2008). In medical news, the relationship is a nascent area of research, and in an Australian context, is emerging (Furlan, 2009; 2011). Much of the literature in this country, as elsewhere, has focused primarily on the quality of medical 
journalism and the consequences of this for the public (Schwitzer et al, 2005; Smith et al, 2005; Wilson et al, 2009; Wilson et al, 2010), rather than on the reporter-PR source relationship. For example, concerns about inaccurate medical stories which lack context, have led concerned US health journalists to formulate a specific code of practice for this specialised form of reportage due to the following perceived problems of medical news dissemination by fellow reporters:

Concerns with sensationalism, commercialism, single-source stories, and interpretation of statistics and medical evidence were among the most frequently cited. Unbalanced, unquestioning coverage of new drugs has been a continuing concern. There is concern about conflicts of interest leading to troublesome entanglements of sponsors, researchers and journalists. (Schwitzer, 2004, p. w10)

Although there are no such ethical guidelines for reporters in Australia to lift standards and help public understanding of medical stories, there have been similar concerns about 'inadequately researched' medical news and their effect on the public, while monitoring the quality of online, TV and print medical news (see Smith et al, 2005; Wilson et al, 2009; Sweet et al, 2009; Wilson et al, 2010). The Australian Press Council (a self-regulatory body of the print media) issued warnings more than a decade ago about using 'extreme care' and the 'most careful treatment' when writing medical news reports and 'the dangers of exciting unreasonable fears or hopes' (Australian Press Council, 2001).

\section{Methodology}

The preliminary findings of mixed method research following an anonymous online survey of 25 purposively-selected medical reporters and 17 public relations practitioners in the health area nationwide, and subsequent indepth interviewing with 15 respondents from both professions, have already been explored elsewhere (Furlan, 2009; 2011). This article explores the reporters' data from both stages of the research through the construct of trust. The journalist respondents in the anonymous online survey were mostly female (84 percent), aged between 35-45 years of age and experienced in their field, with 40 percent having worked as medical reporters for more than a decade. Respondents worked in print (44 percent) radio (16 percent), TV (24 percent) 
or online (16 percent). In the semi-structured interviews with seven medical journalists, more than half were female (57 percent) and the majority $(n=4)$ worked in print (although one participant worked across all media including TV, online, radio as well as print). The rest worked in TV (29 percent) and radio/online (14 percent). This article discusses the attitudes of reporters towards the profession of public relations, public relations practitioners, both in general and on a personal level, through the prism of trust in its permutations regarding optimistic or negative evaluations of the other's anticipated behaviours, intentions and motives (Lewicki, McAllister \& Bies, 1998). The online survey was divided into five sections: Sourcing medical stories; Media releases; Public relations and Medical news; Relationship with PR practitioners; and a section on the demographic information about the survey's participants and whether or not they were willing to take part in further interviews. The indepth interviews explored attitudes, views and perceptions about the relationship with PR practitioners and the profession of public relations generally.

\section{Findings}

Assessment of trustworthiness appears to play a key role in determining the type of relationship which exists between medical journalists and public relations practitioners involved in health promotion. It appears that PR sources who have proved themselves to journalists that they understand the immediacy of news, the requirements of different media (for example, that television reporters need stories with pictures), and who deliver information promptly and accurately as required, are more likely to be used on an ongoing basis. These intermediary sources appear to be regarded as useful informants but only a handful of reporters consider them also dependable, reliable and trustworthy. The type of criticism directed against PR practitioners generally is best summarised by the following print medical journalist:

A lot of PRs have no idea how newspapers work eg deadlines; what we'd need to get a story up such as case studies; photo opportunities suggested are often silly or not appropriate; we never use supplied pics [sic]; PRs often don't research the publications they contact and waste my time pitching things that a newspaper's news section would never run ... PRs should actually READ the papers. (JP2) 
The general contempt and intolerance of public relations was particularly directed at corporate/commercial PR, regarded as self-serving, while there was more tolerance of public relations from not-for-profit organisations or research institutes and hospitals seen as more aligned with the public interest and where peer-reviewed research is conducted. Some journalists regard public relations as a way of getting 'free advertising' as this radio/online medical reporter explained:

My feeling is that PR companies are so poorly regarded by good journalists that they are no longer of any use to the PR companies' clients. What's happened over the last decade is that companies grew tired of spending on advertising budgets and sought to get cheaper and more effective favourable editorial coverage by targeting journalists. (JR1)

When asked in the online survey whether most Australian public relations practitioners are 'ethical and trustworthy', only 16 per cent strongly agreed or agreed. Almost half (48 percent) of the journalist respondents were neutral fence-sitters, while 36 percent disagreed or strongly disagreed. According to Cook, Hardin and Levi (2007) trust 'is most likely to emerge in contexts in which the parties find themselves in ongoing relationships' (p. 4). Three journalists, one working in print, the other two in television news, were positive about the relationship — with certain trusted PR practitioners-which was considered mutually beneficial: 'we both get something out of it' (JTV1). The same television medical reporter noted the importance of relationshipbuilding with PR sources and how trust is a two-way street, describing 'very good' relationships with some of them:

...there's been this trust that's been built up because it's very easy to sensationalise medical stories and they have to trust you not to sensationalise it especially if it's truly a medical breakthrough.... (JTV1)

Similarly, a print journalist observed that relational trust was sometimes crucial in the process of newsgathering:

...they trust me and I trust them and they will give me access to the people I need to speak to and often they're happy for me to have these peoples' mobile number so I can call them anytime. (JP2)

However, this belief was certainly shared by few journalists interviewed: 
It saddens me greatly to see the closeness between a lot of PR people and a lot of journalists, and I think there's unfortunately too often a kind of cosiness that develops... (JP3)

The print reporter (JP3) voiced concerns about other journalists in the field writing stories uncritically, so that the end product is not likely to be a balanced, accurate story and the implications of this for the public. He noted that reporters writing medical or health stories need to be sceptical about the claims that are made by PR people for the products their clients are selling... I think PR's influence is enormous and often its tactics and strategies are invisible' (JP3). Overall, journalist participants defined 'good' public relations practice as one of transparency, honesty and truthfulness with an understanding of media needs, although many thought this was not apparent in practice. Most respondents were negative about public relations practitioners using terms such as "trying to flog something", "spruiking products" and being "obstructionist".

Only three journalists (JP2, JTV 1, JTV2) out of the seven in the semistructured interviews responded affirmatively to the following question: Do you think public relations is important in the process of informing the public about medicine/health? However, two journalists, one working in print the other in TV, qualified their answers:

As long as there's [sic] journalists out there who don't just re-type press releases and actually look at it properly and, you know, check it out. (JP2)

Being able to trust the public relations source is important according to one of the television journalists:

...with medical and research institutes, they have a lot more credibility, the research is done there, you're talking to people who are actually doing the research and you know, I feel more comfortable with those people than the independent PR agencies. (JTV1)

The other television reporter summarised the usefulness of PR practitioners:

They definitely do help smooth the way between the raw information, which is obviously very technical information, getting that out to the media who can make that understandable for the public which should be the aim. (JTV2) 
The remaining four participants were all negative about the need for public relations in order to inform the public about medical/health news, pointing out how the professions have different and often incompatible goals. One reporter observed that the 'most responsible, ethical, balanced journalism does not come from PR sources' (JR1).

\section{Discussion and conclusion}

Journalists in this study acknowledged the prevalence of public relations in medical/health reporting in Australia, but did not trust its practitioners overall, especially those with corporate or commercial clients. Those who had developed ongoing relationships with regular PR sources were more willing to look at public relations positively and consider individuals trustworthy. Further, those journalists were inclined to discuss the importance of trust also from the public relations perspective regarding the reporters' own reliability, credibility and dependability in the medical field, considered as having a heightened sense of public responsibility — since 'peoples' health is at stake' (JP3).

The news media play an important role in bringing public visibility to the latest medical/health information, in setting the agenda about what is considered topical and important and in improving health literacy (Wang \& Gantz, 2007; Levi, 2001). Reciprocal trust expressed by only a few reporters in this study, illustrates the willingness to barter in the relationship with PR confidantes in order to avoid the risk and uncertainty of not getting the story or access to sources. Even participants in this study who were the most sceptical about public relations, recognised the importance of having cordial relations with PR practitioners in order to obtain the information needed and interviews with crucial, elite sources when necessary. However, long-term opponents who view each other with cynicism are unlikely to trust each other or 'to believe that a cooperative gesture is not a ruse or setup for future exploitation' (Lewicki et al., 2006, p. 98). As Cook et al. (2007) point out, even though trust predicates an exposure to vulnerability in the relationship, as one can never be 100 percent certain of the trustee's intentions or motives, repeated interactions demonstrating predictable dependability, competence and reliability, offers the trustor confident and positive expectations of the trustee's behaviour.

However, it also appears that both trust and distrust can co-exist in the dyadic PR source-reporter relationship in the specialised field of medical 
journalism, with a state of distrust not necessarily preventing collaboration. Lewicki et al (1998) observed that, rather than being mutually exclusive and opposite conditions, trust and distrust should be seen as co-existing constructs, depending on the situation. For example, you may trust a doctor's advice on medical treatments but not on financial investments. A few reporters in this study expressed positive opinions about regular PR sources considered trustworthy, but also included self-imposed caveats on the 'trust' condition, for example, by stressing the need to critically appraise information and independently verify facts (a fundamental professional tenet of normative practice in journalism) even of those they may consider trustworthy. Similarly, participants who generally distrusted PR sources, recognised the need to sometimes deal with them and the information on offer in a suitably trusting manner. According to Cook et al (2007), distrust (evident in the opinions and perceptions of most of the journalist participants about PR sources) can be 'good and protective' (p. 60). One can therefore extrapolate that the professional norms of truth-telling and fair, balanced, critical reporting in journalism remain intact if distrust is present. However, distrust can also 'be pervasive, and it can block possibilities for social cooperation and even for social order' (Cook et al., 2007, p. 62). Similarly, Hardin (2001) notes that 'potentially, trust is far more productive than distrust [sic] in the following sense: acting on distrust leads to foregone opportunities; acting on trust can lead to successful and mutually beneficial interactions' (p. 498). A culture of distrust may mean that potential cooperation between a reporter and PR source (who may have legitimate stories of public interest) may not even be considered and the opportunity to disseminate appropriate and timely health/medical messages through the news media is denied, due to intractable prejudices which have soured the relationship (White \& Hobsbawm, 2007).

According to participants in this study, relationships of trust between medical reporter and PR sources are developed over time and may take years to nurture but seem uncommon. Cho and Cameron (2007) found 'regular contact' between the professions in medical/health news production 'breeds close relationships, respect and trust' (p.182). Nonetheless, for most of the journalist participants in this research, the state of trust is elusive and difficult to cultivate, despite interdependency at times. As Charron (1989) posits:

Journalists and public relations officers find themselves mutually dependent on one another, a situation which demands cooperation, 
while their divergent control interests cause distrust and opposition.

(Charron, 1989, p. 43)

Having divergent interests and cultures, one seeking the story, the other publicity, makes the relationship (whether for a one-off experience or on-going) complex and dichotomous, with trust-distrust, conflict-cooperation, sometimes present simultaneously.

Although determining the public effects of specific medical news produced by reporters using PR information is beyond the scope of this current study, it could be an area of future research focus. There is evidence that in Australia, as elsewhere, pre-packaged public relations information is increasingly being used and sometimes uncritically, in medical news production (Bacon et al., 2010; Holmes, 2008; Lewis et al., 2008). Almost three quarters of respondents in this study determined that more than 50 percent of medical news in Australia has its origins in public relations even though they downplayed the influence in their own newsgathering (Furlan, 2009). Wilson et al. (2010) posit that the bulk of medical/health stories in Australia are written by generalist reporters but that stories written by specialist medical reporters 'were superior to those written by other groups' (p. 2). Notwithstanding, medical news can have profound effects on public behaviours and understandings of health issues, treatments, drugs, devices and the latest research. How public relations information is presented to medical reporters and how they use that information can affect the type of story that is published (Kopenhaver et al., 1984, p. 884).

The miscommunication of medical news which is inaccurate, sensational or biased has inherent implications for public access to reasoned, informed debate. The reporting of medical news has an added sense of responsibility given the public is susceptible to changing behaviours, medications and opinions on the basis of a published story, often with regrettable consequences, as illustrated at the beginning of this paper. The Australian Code of Ethics, outlined earlier, states that journalists 'scrutinise power, but also exercise it, and should be accountable. Accountability engenders trust. Without trust, journalists do not fulfil their public responsibilities' (Media Alliance Code, 2012). Trust is therefore an important construct, not only to facilitate collaboration between the professions in order to produce a comprehensive, balanced, reliable news story in context and complete, but also as a core journalistic obligation to maintain the public's collective trust, not necessarily on an individual level, 
but on the 'system of expertise that produces and maintains the role-appropriate behaviour' of those within the profession (Kramer, 2010, p.89) and what is rightly expected of the Fourth Estate in a democracy.

\section{References}

Arroyave, J. (2012). Health, news and media information. In Obregon, R. \& Waisbord, S. (Eds.), The Handbook of Global Health Communication (pp. 194-214). Chichester: Wiley-Blackwell.

Australian Press Council (2001), Reporting guidelines, 'Health Warning'. General Press Release No. 245 [April]. Retrieved on 29 September 2011, from www. presscouncil.org.au/document-search/guideline-health/?LocatorGroupID=662\& LocatorFormID $=677 \&$ FromSearch $=1$

Bacon, W. Taylor, A. \& Pavey, S. (2010). Media snapshot: How we analysed the spin cycle, Crikey.com. Retrieved on 29 September 2011, from www.crikey.com. au/2010/03/15/media-snapshot-how-we-analysed-the-spin-cycle/

Bedford, H. \& Elliman, D. (2010). MMR vaccine and autism. BMJ 2010;340:c655. Brants, K. \& Yael de Haan (2010). Taking the public seriously: Three models of responsiveness in media and journalism. Media, Culture \& Society, 32(3), 411-428.

Burton, B. (2007). Inside spin: The dark underbelly of the PR industry. Crows Nest, NSW: Allen \& Unwin.

Charron, J. (1989). Relations between journalists and public relations practitioners: Cooperation, conflict and negotiation. Canadian Journal of Communications, 14, no. 2.

Cho, S. and Cameron, G. (2007). Power to the people-health PR people that is!, Public Relations Review, 33(2), pp. 175-183.

Cook , K., Hardin , R. \& Levi , M. (2007). Cooperation without trust. New York: Russell Sage Foundation.

Davies, N. (2008). Flat earth news. London: Chatto \& Windus.

Davis, A. (2003). Public relations and news sources. In S. Cottle (Ed.), News, public relations and power (pp. 27-42). London: Sage.

DeLorme, D. \& Fedler, F. (2003). Journalists' hostility toward public relations: An historical analysis, Public Relations Review, 29, pp.99-124.

Editors, The Lancet (2010). Retraction-Ileal-lymphoid-nodular hyperplasia, nonspecific colitis, and pervasive developmental disorder in children. February 6; 375(9713), 445. Published online February 2, 2010. DOI:10.1016/S01406736(10)60175-4

Furlan, P. (2009). Feeling the pulse: Journalists, public relations practitioners and medical news reporting. Australian Journalism Review, 31(2), pp. 61-74.

Furlan, P. (2011). Reporting medical stories in Australia. What is the place of public relations? Paper presented at the 2011 July ANZCA conference, 'Communication on the edge: Shifting boundaries \& identities,' Hamilton, New Zealand. 
Refereed paper published online: www.anzca.net/conferences/past-conferences/114anzca11-proceedings.html

Guth, D. and Marsh, C. (2003). Communication: The tactics of public relations. In Public relations, a values-driven approach (pp. 262-302) [2nd Edition)]. Boston, USA: Allyn \& Bacon, Pearson Education Inc.

Hardin, R. (2001). Distrust. Boston University Law Review, 81: pp. 495-522.

Holmes, J (2008). Media Watch, www.abc.net.au Gilding the lily, Episode 14, broadcast 19 May 2008: www.abc.net.au/mediawatch/transcripts/s2249537.htm

Hon, L. and Grunig, J. (1999). Guidelines for measuring relationships in public relations. Gainsville, Fl: The Institute for Public Relations Commission on PR Measurement and Evaluation, University of Florida.

Hung, F. (2005). Exploring types of organisation-public relationships and their implications for relationship management in public relations. Journal of Public Relations Research, 17(4), pp. 393-425.

Kees Brants and Yael de Haan (2010). Taking the public seriously: Three models of responsiveness in media and journalism. Media, Culture \& Society, 32(3): pp. 411-428. Kopenhaver, L. L., Martison, D. L., and Ryan, M. (1984). How public relations practitioners and editors in Florida view each other. Journalism Quarterly, 61(4), pp. $860-865,884$.

Ledingham, J \& Bruning, S (1998). Relationship management in public relations: Dimensions of an organisation-public relationship. Public Relations Review, 24(1), 55-65.

Lee, J., Melgaard, B., Clements, C., Kane, M., Mulholland, E. and Olive, J. (1998). Autism, inflammatory bowel disease, and MMR vaccine. The Lancet, 351(9106), 905.

Lewicki, R. J., McAllister, D. J., and Bies, R. J. (1998). Trust and distrust: New relationships. The Academy of Management Review, 23(3), 438-458.

Lewis, J., Williams, A., \& Franklin, B. (2008). A compromised fourth estate? Journalism Studies 9(1), pp. 1-20.

Kramer, R. and Cook, K. (2004) Trust and distrust in organisations: Dilemmas and approaches. New York: Russell Sage Foundation.

Kramer, R. (2010). Collective trust within organisations: Conceptual foundations and empirical insights. Corporate Reputation Review, 13(2), pp. 82-97.

Levi, R. (2001). Medical journalism: Exposing fact, fiction, fraud. Ames, Iowa: State University Press.

Lewis, J., Williams, A., and Franklin, B. (2008). A compromised fourth estate? Journalism Studies, 9(1), pp. 1-20.

Macnamara, J. (2012). Journalism and public relations: unpacking myths and stereotypes. Australian Journalism Review, 34(1), pp. 33-50.

Marconi, J. (2004). Publicity and the media. In Public relations: The complete guide (pp. 136-135) Masor, Oh: Thomson.

Mayer R., Davis J. and Schoorman F. (1995). An integrative model of organisational trust. The Academy of Management Review, 20:709-34. 
Media Alliance Code of Ethics. (2012). MEAA (Media, Entertainment and Arts Alliance). Retrieved on 10 September 2012, from www.alliance.org.au/code-ofethics.html

Morgan, R. (2012). Image of professions. Survey: www.roymorgan.com/news/ polls/2012/4777/

Plaisance, P.L. and Skewes, E.A. (2003). Personal and professional dimensions of news work: exploring the link between journalists' values and roles. Journalism \& Mass Communication Quarterly, 80(4), pp. 833-848.

Putnam R. (1993). Making democracy work: Civic traditions in modern Italy. Princeton, NJ: Princeton University Press.

Richards, I. (2010). The strange case of trust in journalism. In Fortner R. and Fackler, M.(Ed.), Ethics and evil in the public sphere: Media, universal values and global development (pp. 79-92). NJ: Hampton Press.

Smith, David E., Wilson, Amanda J. and Henry, David A. (2005). Monitoring the quality of medical news reporting: early experience with media doctor. Medical Journal of Australia, 183(4), pp. 190-193.

Schultz, J. (1998). Reviving the fourth estate: Democracy, accountability and the media. Cambridge: Cambridge University Press.

Schwitzer, G.(2004). A statement of principles for health care journalists. The American Journal of Bioethics, 4(4), W9-W13.

Schwitzer, G., Mudur, G., Henry, D., Wilson, A., Goozner, M., Simbra, M., Sweet, M., and Baverstock, K. (2005). What are the roles and responsibilities of the media in disseminating health information? PLoS Medicine, 2(7), pp. 576-582.

Shin J. \& Cameron, G. (2004). Conflict measurements: Analysis of simultaneous inclusion in roles, values, independence, attitudes, and dyadic adjustment. Public Relations Review, 30(4), pp. 401-410.

Shin, J. H., and Cameron, G. (2005). Different sides of the same coin: Mixed views of public relations practitioners and journalists for strategic conflict management. Journalism \& Mass Communication Quarterly, 82(2), pp. 318-338.

Sigal, L. (1973). Reporters and officials. Lexington, MA: D.C. Heath.

Sterne, G. (2010). Media perceptions of public relations in New Zealand. Journal of Communication Management, 14(1), pp. 4-31.

Sweet, M.A., Chapman, S., Moynihan, R. and Green, J. H. (2009). CHAMP: A novel collaboration between public health and the media. Medical Journal of Australia, 190(4), 206-207.

Tanner, A. (2004). Agenda-building, source selection and health news at local television stations: A nationwide survey of local television health reporters. Science Communication, 25(4), 350-363.

Tilley, E. \& Hollings, J. (2008). Still stuck in 'a love-hate relationship': Understanding journalists' enduring and impassioned duality towards public relations. Paper delivered at ANZCA08, 'Power and Place: Refereed proceedings'. Retrieved on 27 September 2009, from http://anzca08.massey.ac.nz

Uhlmann, D. (2011). After the spill is gone: The Gulf of Mexico, environmental crime, and the criminal law. Michigan Law Review, 109, p. 1413. 
Vanacker, B. \& Belmas, G. (2009). Trust and the economics of news. Journal of Mass Media Ethics, 24, pp. 110-126.

Wakefield, A. J., Murch, S. H., Anthony, A., Linnell J., Casson, D. M., Malik, M., Berelowitz, M., Dhillon A. P., Thomson, M. A., Harvey, P., Valentine, A., Davies, S. E., and Walker-Smith, J. A. (1998). Ileal-lymphoid-nodular hyperplasia, nonspecific colitis, and pervasive developmental disorder in children. The Lancet. Feb 28; 351(9103), pp. 637-41

Wang, Z. \& Gantz, G. (2007) Health content in local television news. Health Communication, 21(3), pp. 213-221.

White, J., and Hobsbawm, J. (2007). Public relations and journalism. Journalism Practice, 1(2), pp. 283-292.

Wilson, A, Bonevski, B., Jones, A., and Henry, D. (2009). Media reporting of health interventions: signs of improvement, but major problems persist. PLoS ONE, March, 4(3). www.plosone.org pp. 1-5

Wilson, A, Robertson, J., McElduff, P., Jones, A. and Henry, D. (2010). Does it matter who writes medical news stories? PLoS, September, 7(9), e1000323, 1-5.

Yoon, Y. (2005). A scale for measuring media relations efforts. Public Relations Review, 31(2005), pp. 434-436.

Patrizia Furlan is a lecturer in journalism, School of Communication, International Studies and Languages at the University of South Australia. Her PhD project focuses on the relationship between journalists and public relations practitioners.

Patrizia.Furlan@unisa.edu.au 
Copyright of Pacific Journalism Review is the property of Auckland University of Technology and its content may not be copied or emailed to multiple sites or posted to a listserv without the copyright holder's express written permission. However, users may print, download, or email articles for individual use.

http://www.aut.ac.nz/depts/commstud/journ/pjrsubs.shtml 